\section{La Universidad Nacional de La Plata en el contexto actual: la búsqueda de un modelo inclusivo}

\section{Fernando Tauber}

Vicepresidente del Área Institucional

de la Universidad Nacional de La

Plata, Argentina.

fernando.tauber@presi.un/p.edu.ar
A 100 años de la Reforma Universitaria de 1918 /

Desafíos de gestión

RECEPCIÓN: 20/06/17

ACEPTACIÓN FINAL: 24/07/17

\section{Resumen}

Las universidades públicas en América Latina están atravesadas por modelos neoliberales y humanistas en los extremos y múltiples variantes de ellos que en muchos casos articulan ambos puntos de vista. La Universidad Nacional de La Plata (UNLP), fundada como una institución moderna, ha incorporado para su funcionamiento administrativo y académico la concepción reformista de universidad pública.

La Reforma Universitaria de 1918 es soporte ideológico y material esencial para el fortalecimiento y consolidación de la democratización, la autonomía, la masividad y la calidad de la educación, no solo en Argentina sino también en el resto de Latinoamérica y el mundo.

Haciendo hincapié en la importancia que este acontecimiento tuvo en la historia, en el presente documento compartimos, en una primera parte, un breve recorrido por la historia de la educación superior. Luego nos detendremos en el caso de la UNLP y profundizaremos en la extensión universitaria y su crecimiento, que han hecho posible la integración con la comunidad en una condición solidaria, interactiva y formativa.

\section{Palabras clave}

- Universidad Nacional de La Plata

- Educación pública, libre y gratuita

- Extensión universitaria

- Reforma Universitaria

\section{Resumo}

As universidades públicas na América Latina são atravessadas por modelos neoliberais e humanistas nos extremos e múltiplas variantes deles que em muitos casos articulam ambos os pontos de vista. A Universidad Nacional de La Plata (UNLP), fundada como uma instituição moderna, incorporou para o seu funcionamento administrativo e acadêmico a concepção reformista de universidade pública. A Reforma Universitária de 1918 é suporte ideológico e material essencial para o fortalecimento e consolidação da democratização, a autonomia, a massividade e a qualidade da educação, não só na Argentina como também no resto da América Latina e no mundo. Salientando a importância que este acontecimento teve na história, no documento a seguir compartilhamos em uma primeira parte, um breve percurso pela história da educação superior. Depois nos deteremos no caso da UNLP e aprofundaremos na extensão universitária e o seu crescimento, que têm possibilitado a integração com a comunidade em uma condição solidária, interativa e formativa.

\section{Palavras-chave}

- Universidad Nacional de La Plata

- Educação pública, livre e gratuita

- Extensão universitária
Para citación de este artículo

Tauber, F. (2017). La Universidad Nacional de La Plata en el contexto actual: la búsqueda de un modelo inclusivo. Revista $+E$ versión en línea, 7(7), 132-143 Santa Fe, Argentina: Ediciones UNL. 


\section{Introducción: la evolución histórica de las universidades}

El siglo XX tuvo como características determinantes la explosión demográfica en el mundo, la urbanización de la población, la degradación ambiental y una impresionante aceleración en los procesos tecnológicos. Esto condicionó fuertemente el desarrollo social y educativo, dio un nuevo alcance a la dimensión cultural y a las cuestiones de política y poder de las instituciones, y modificó en consecuencia los métodos de planificación y gestión del desarrollo comunitario y de sus instituciones — considerando en particular las de educación superior.

El pensamiento moderno, cartesiano e iluminista, dominante en la primera mitad del siglo, visualizó al mundo como una totalidad esencialmente ordenada y a los procesos de desarrollo de la sociedad - y de sus instituciones- desde una visión de certidumbre en el futuro, homogéneo y previsible, como resultado de una suma de tendencias y decisiones.

Durante la segunda mitad del siglo, con la aceleración de los procesos tecnológicos y una saturación demográfica del territorio urbano, surgió como alternativa sustituta y consecuente el pensamiento posmoderno, un sujeto crítico que visualizó al mundo ya no como una totalidad sino como un número ilimitado de modelos de orden, cada uno de los cuales era generado por un conjunto relativamente autónomo de prácticas comunitarias. Esos procesos de desarrollo fueron comprendidos así desde una visión de "incertidumbre", en la que se consolidó la pluralización de los discursos contextualizados por la comunidad y la tradición, que postuló el carácter local de la verdad, el juicio y el gusto.

En ese contexto, las universidades tuvieron un desarrollo explosivo en las últimas décadas — principalmente en los últimos 30 años- que trajo aparejado un gran crecimiento de ciudadanos en el acceso a la educación superior.

Como se señala, los factores que promovieron ese proceso fueron: el crecimiento demográfico; la urbanización de la sociedad; la aceleración de los avances en ciencia y tecnología; el ingreso de las mujeres al mercado laboral; la generalización y expansión gradual de la educación formal y preuniversitaria; el desarrollo de una cultura juvenil; el movimiento de adultos para adquirir nuevas calificaciones, certificaciones y oportunidades de trabajo; las nuevas y consecuentes capacidades requeridas por la industria y los servicios modernos; el crecimiento económico de algunos países históricamente postergados; y la certeza generalizada de que el desarrollo va asociado a la educación superior, de que la formación universitaria y el crecimiento científico tecnológico son indispensables para producir cambios sociales, culturales, políticos y económicos.
En estas últimas décadas, "la universidad ha pasado a ocupar un papel tal vez más destacado que en cualquiera otra época de la historia" (Hübner Gallo, 1963:7) y

"si bien quizá todavía no sea posible pensar en la educación superior como un sistema global, existe una importante convergencia entre las universidades del mundo y los sistemas de educación superior". (Altbach y Davis, 2000:22)

Sin embargo, en la convergencia contemporánea de los distintos tipos históricos de universidad,

"a grandes líneas observamos en la actualidad dos modelos de educación que se enfrentan: el neoliberal, que conduce a una educación en destrezas y habilidades técnicas para producir una profesionalidad pragmática, empiristas de la sociedad de mercado; y el modelo humanista, cuyo paradigma es la educación en valores, que ve las humanidades no sólo como disciplinas, sino como formación básica y ética que oriente los saberes específicos y forje un 'profesional social'". (Rojas Mix, 2006:18)

Entre estos dos extremos, hay múltiples tipos de universidades que, en muchos casos, articulan ambos puntos de vista.

Tal es el caso de América Latina, donde estos modelos se entrecruzan, potencian y acentúan las contradicciones generales que conviven en nuestra sociedad. Por ejemplo, en su momento, la vigencia de las más encendidas luchas reivindicatorias (no solo por intereses universitarios sino por políticas generales de cambio para nuestros países) reemplazaron el debate en el ámbito de la universidad pública por las tomas ${ }^{1}$ de facultades, la interrupción permanente del funcionamiento institucional y muchas veces la violencia y la agresión en la relación cotidiana. Estas situaciones, en reiteradas oportunidades, llevaron a la universidad pública — gratuita en la Argentina - a crisis tales que vaciaron sus aulas de alumnos, lo cual propició claramente el crecimiento de una universidad privada con acentos diferentes en el modelo de educación buscado por estas instituciones públicas: inclusivo, promotor de una movilidad social ascendente y al servicio incondicional de la sociedad y del desarrollo del país.

En el análisis de la evolución histórica de las universidades pueden identificarse al menos tres períodos entendidos como verdaderas revoluciones académicas debido a la gran transformación institucional que impusieron en las actividades de generación, transmisión y utilización del conocimiento avanzado.
1) En Argentina se denomina "toma de facultad" a una forma de protesta desarrollada por un grupo social vinculado a la institución. Esta acción implica la instalación de este grupo en el edificio impidiendo total o par- cialmente su funcionamiento habitual, tanto administrativo como académico. Las "tomas de edificios" son una forma de protesta común, decidida mediante asamblea y puede ocurrir en cualquier institución pública o privada. 
La primera revolución la produce el propio origen occidental de las universidades en el apogeo del período medieval, con la creación de la Universidad de Bolonia en 1088 y la de París en 1150, a partir de:

1) El redescubrimiento por los europeos, a través del Islam, de la cultura de la Antigüedad, lo cual dio lugar a que a partir del siglo XII se formalizaran las instituciones universitarias (Kuhn, 1985).

2) El cambio cultural expresado por las formas de pensar y de enseñar que conforman la escolástica basada en la dialéctica en tanto "ciencia del razonamiento".

3) La afirmación del poder ideológico de la Iglesia en la Cristiandad de Occidente (Arocena y Sutz, 2001).

4) El surgimiento de la ciudad medieval como fenómeno específico (Pirenne, 1992), en el que "la organización universitaria del siglo XII marca la integración de la vida intelectual a la vida de la ciudad" (Le Goff, 1965).

La segunda revolución la produce la idea alemana del siglo XIX de incorporar la ciencia y la investigación a la enseñanza universitaria, con la fundación de la Universidad de Berlín en 1810 por parte de Wilhelm von Humboldt, que consistió esencialmente en la gran transformación que supone vincular la generación de conocimientos con su transmisión al más alto nivel como dos aspectos de una misma tarea realizada por la misma gente en la misma institución.

"En ocho siglos de vida universitaria en el mundo occidental, desde las Bolonia y París del siglo XII hasta las Stanford y Tokio del siglo XX, ningún otro cambio se puede comparar con el surgimiento y desarrollo de la moderna universidad de investigación." (Clark, 1997:9)

La tercera revolución, a mi juicio, la produce la Reforma Universitaria de 1918 en Córdoba, ${ }^{2}$ Argentina. Significó la erradicación de la Teología ${ }^{3}$ y la introducción, en lugar de esta, de directrices positivas: la ampliación y diversificación de las modalidades de formación profesional, el intento de institucionalizar el cogobierno de la universidad por sus profesores y estudiantes, la implantación (más verbal que real por esos tiempos) de la autonomía de la universidad referente al Estado, la reglamentación del sistema de concursos para el ingreso a la carrera docente y, en general, una mayor democratización de la enseñanza (Ribeiro, 1971).
A estos grandes cambios se suma también una serie de conquistas que rematan con la "misión social de la universidad", que incorpora así la extensión universitaria y la preocupación por centrar en la universidad el espacio natural de promoción de los debates de los temas que preocupan a la sociedad. Esta figura dio forma y fundamento al modelo de universidad contemporánea, particularmente en América Latina, el cual condiciona nuestras instituciones hasta nuestros días.

La concepción reformista de universidad pública toma cuerpo en todo el continente, se transforma en el objetivo a alcanzar por las universidades públicas de la América de habla hispana y es una referencia en muchos de sus objetivos para el resto de las instituciones de educación superior en el mundo.

La universidad en América Latina nació como institución colonial al servicio tanto de la Iglesia como de la Corona. En ella, la Iglesia cumplió un rol gerencial central y excluyente durante tres siglos hasta la emancipación, formó a la elite criolla clerical y, en sus últimos tiempos, también a la dirigente. Evolucionó como institución republicana en el siglo XIX, poniéndose al servicio del Estado y formando a sus elites dirigentes.

Recién en el siglo XX se transformó en un instrumento de movilidad social, integró a la ciencia y paulatinamente puso la producción de conocimientos al servicio del desarrollo nacional y del progreso social, aunque aún despliega un perfil marcadamente profesionalista. Evoluciona en el siglo XXI hacia la integración regional y la internacionalización, asimilando el proceso de globalización como contexto potenciador de su aporte, consolidando la producción científica, tecnológica y artística y el compromiso social como sus objetivos, que se suman a la enseñanza como fundamentales.

En ese contexto, la universidad en la Argentina se afianzó y evolucionó durante el siglo XX fundamentalmente a partir de la Reforma de 1918, pero fue el reflejo de la inestabilidad democrática del país, plena de golpes militares y gobiernos de facto alternados con gobiernos populares y populistas. Confirmó su perfil reformista recién en la década del '60, el que se vio interrumpido por casi 20 años, por una época dolorosa de represión e intervención de las instituciones, que culminó con el actual proceso democrático iniciado en 1983, período en el cual se consolidó el actual modelo de universidad argentina y su rol en la región.
2) No se registra en el siglo $X X$ otro movimiento generado en las universidades de tamaña significación e influencia. El desarrollo contemporáneo de la educación superior en Asia, África y Oceanía transcurrió con importantes esfuerzos para poder 'popularizarse' y salir del modelo de 'elite colonial', avances conseguidos a partir de la evolución política y social de los Estados. En Europa, cuna de la universidad occidental, el período transcurrió entre las guerras mundiales de las que fue escenario y la posterior 'guerra fría'.

El 'Mayo Francés' del 68, por ejemplo, a pesar de su magnitud, no tuvo repercusión continental en el sistema universitario (ni siquiera en Francia).
3) En Europa, cuna de la Universidad de América Latina, la enseñanza de la Teología se había relativizado como obligatoria ya en el siglo XVII, con la consolidación de los Estados. Sólo sobrevivía en ciertas universidades. En América Latina, sin embargo, a pesar del período de consolidación republicana en el siglo XIX, la fuerte impronta 'colonial' del proceso de nacimiento de las universidades, donde la presencia de la iglesia fue determinante, hizo que la obligatoriedad de su enseñanza perdurara, desfasándose del rol que la propia sociedad daba a las universidades. 
En este último período, el documento más importante para la reflexión y la defensa de la educación superior en el mundo es, hasta el momento, la primera Conferencia Mundial sobre Educación Superior, organizada por la UNESCO en París en 1998, continuado y consolidado en la segunda Conferencia Mundial sobre Educación Superior, convocada también por la UNESCO en 2009.

Plantea que las respuestas de las universidades a un mundo en constante cambio, caracterizado por una demanda masiva de educación superior, deberían guiarse por cuatro consignas: pertinencia, calidad, internacionalización o cooperación interuniversitaria y acceso. Postula que la igualdad de condiciones para el acceso y permanencia en los estudios debe estar basada en los méritos, la capacidad, los esfuerzos, la perseverancia y la determinación de los aspirantes.

Con ese marco de referencia, define una serie de características necesarias para el desarrollo del proceso educativo y condiciona la mejora y conservación de la calidad de la enseñanza, de la investigación y de la vinculación social de la educación superior, a un financiamiento suficiente por parte del Estado, a una autonomía real de las instituciones para manejar sus asuntos, y al desarrollo de competencias de gestión eficaces, que exijan a la universidad la elaboración de capacidades y estrategias apropiadas de planificación y análisis de sus políticas.

Esa condición es profundizada en el plano de los sistemas y las instituciones, donde considera especialmente que los Estados deberán garantizar el hecho contar con un plan que defina su objetivo, misión, estrategias y prioridades; considerando 1) el respeto a la ética, al rigor científico e intelectual, al enfoque multidisciplinario y transdisciplinario, al acceso, a la calidad y a la pertinencia; 2) el desarrollo sostenible de la sociedad; 3) la articulación en la tarea docente de la enseñanza con la investigación y la extensión; 4) la orientación, la integración, la asociación con el mundo del trabajo y el apoyo a los graduados; 5) la calidad de las normas institucionales; y 6) la promoción y desarrollo de la investigación y la generalización de las nuevas tecnologías.

En síntesis, estos años de democracia consolidaron en América Latina, y en particular en nuestro país, a la educación superior como un bien público social, un derecho humano universal y un deber del Estado.
El pedagogo Francisco Giner de los Ríos definía a la universidad como "la conciencia ética de la vida" (Rojas Mix, 2008). En ese sentido, la educación superior, a través de sus funciones de docencia, investigación y extensión, desarrolladas en contextos de autonomía institucional y libertad académica, no solo debe incrementar su mirada interdisciplinaria y proveer de competencias sólidas al mundo presente y futuro sino que también debe contribuir a la formación de individuos capaces, aptos para seguir mejorando por sí mismos y para insertarse como elementos útiles y factores de superación en el tejido social (Lima, 1995), de ciudadanos éticos y activos, con pensamiento crítico y comprometidos con valores universales tales como la igualdad, la solidaridad, el respeto a la dignidad de las personas y la defensa de los derechos humanos, de la paz, de la libertad y de los valores de la democracia, lo cual debería contribuir al diálogo intercultural y al logro de un mayor desarrollo humano sustentable (UNESCO, 2009).

Se trata de que la universidad forme científicos, tecnólogos, profesionales, intelectuales y artistas sociales intelectualmente preparados. Que tengan la sensibilidad, el conocimiento, la habilidad y la experiencia adecuados para ejercer con eficiencia sus destrezas, capaces de aprender a aprender a lo largo de toda la vida, y conscientemente orientados en sus valores ciudadanos, bien informados y profundamente motivados. Provistos además de un sentido crítico y preparados para analizar y buscar soluciones a los problemas de la sociedad en un mundo básicamente cambiante y para asumir responsabilidades sociales crecientes (UNESCO, 1995).

La universidad, en definitiva, debe formar seres pensantes, capacitados para evaluar y discernir entre diversas opciones pero también para desarrollar otras nuevas (Brovetto, 1998), "líderes, agentes de cambio: hombres y mujeres dispuestos a asumir riesgos para construir un mundo mejor" (Marcovitch, 2002:17). "Que un país afirme que tiene seres pensantes en exceso y que esto lo plantee como una desventaja, más que descabellado es ridículo" (Lima, 1995:11).

En ese proyecto se inscribe nuestra universidad pública, identificada con valores como el saber, la libertad, la creatividad, la responsabilidad individual, la tolerancia y la participación (Martínez Nogueira, 2003), tratando de "ser cada vez más científica y a la vez más comprometida socialmente" (Krotsch, 2001:142-143), de estar 


\section{C6}

La universidad que promovemos

está estrechamente vinculada a las

circunstancias locales, aunque plenamente

comprometida con la búsqueda universal

de la verdad y el avance del conocimiento más relacionada internacionalmente y más involucrada localmente. Nuestro modelo es el de una universidad abierta a todas las ideas y a todas las discusiones, cuyo cometido esencial sea la enseñanza, validada por la investigación y la extensión, y al servicio de una mejor calidad de vida para toda la sociedad en la que está inserta y de la que se nutre (Lima, 1995).

La universidad que promovemos está, en consecuencia, estrechamente vinculada a las circunstancias locales, aunque plenamente comprometida con la búsqueda universal de la verdad y el avance del conocimiento. Es fundamentalmente un ámbito para pensar, tener ideas y discutirlas, y un espacio "de inquietudes, rechazos, audacias, escrúpulos y esperanzas” (Bayen, 1978:150151) que es necesario comprender en su verdadera dimensión y reconocerla por estas condiciones como factores determinantes para el progreso.

En nuestro país, la razón de ser de la universidad pública es servir a la comunidad y ayudarla a progresar. Sus objetivos esenciales se sintetizan en formar estudiantes y graduados como ciudadanos con valores éticos y sociales firmes y con un fuerte espíritu crítico; en lograr generar más y mejor conocimiento, transferirlo y que sea eficaz para producir desarrollo y progreso social; en estar cada vez más cerca de la comunidad y ayudar en sus necesidades más urgentes; en lograr que más jóvenes ingresen, que más estudiantes permanezcan y que más graduados egresen de la universidad, sin resignar calidad —excelencia y pertinencia- en lo que se enseña. Nuestra sociedad tendrá más oportunidades de progresar si sus miembros saben más y si están mejor formados, y es la universidad pública y autónoma la que debe hacer ese aporte. Ese es el desafío contemporáneo de la universidad pública latinoamericana y, en ese contexto, de la Argentina.

\section{La Universidad Nacional de La Plata en el centenario de la Reforma Universitaria}

Hacia el centenario de la Reforma Universitaria, las universidades públicas tienen la obligación de reflexionar y resignificar los conceptos básicos que desarrollaron los reformistas del '18. En este sentido, la UNLP debate y genera políticas públicas fundadas en aquellos ideales pero repensadas en el contexto actual de la educación Superior.

Las palabras que se exponen a continuación tienen como fin ilustrar este recorrido.

\section{El ideario de la Reforma}

La UNLP es pública, autónoma, cogobernada y reformista. Pero ¿qué significa ser "reformista" a 100 años de la Reforma Universitaria de 1918? Por un lado, significa que los pilares conceptuales de la revolución universitaria más importante de la historia de América Latina - y una de las fundamentales para moldear el modelo de universidad pública que exponemos al mundo- se sostienen con firmeza, se consolidan a medida que la universidad pública avanza y se complementan con otras metas contemporáneas que orientan al modelo de institución que requiere nuestro pueblo.

La Reforma del '18 predicó sobre la autonomía, el cogobierno, el ingreso irrestricto, la gratuidad, la libertad de cátedra, el acceso a la enseñanza por concurso, la extensión universitaria, la discusión en su ámbito de los temas que le preocupan a la sociedad. Muchas de sus proclamas se fueron cumpliendo a lo largo de todo este siglo. Algunas se adecuaron a nuestra realidad actual; sin embargo, son el cuenco tallado, el molde sagrado en el que se vierte el esfuerzo constante por desarrollar la universidad de nuestro tiempo. 


\section{Hoy la solidaridad es un valor indispensable para un universitario porque ser universitario de una universidad pública es una condición privilegiada en una sociedad de desiguales}

Su Manifiesto Liminar, escrito por los estudiantes revolucionarios de las primeras décadas del siglo XX, inculcó para siempre que lograr una libertad más es tener una vergüenza menos y que siempre habrá mucho por sumar, que los dolores que nos quedan son las libertades que nos faltan, y que siempre habrá cadenas por romper para lograr una sociedad más justa, más igual, más feliz y plena. Hoy la Reforma exige que defendamos a la universidad pública como una herramienta indispensable para el desarrollo de nuestra comunidad, de nuestra Patria. Hoy la solidaridad es un valor indispensable para un universitario, pero no como condición humana universal, sino porque ser universitario de una universidad pública es una condición privilegiada en una sociedad de desiguales. Esta solidaridad tan necesaria debe ser una circunstancia.

La solidaridad que pide la Reforma no es sinónimo de caridad, de la caridad del privilegiado en la certeza de que siempre habrá oprimidos. Es el brazo que ayuda a subir al bote a esas mayorías que se ahogan en la injusticia social y les hace un lugar en el banco que pudimos ocupar para compartir de igual a igual el esfuerzo de remar y remar para llegar más rápido a ese lugar que los universitarios soñaron hace 100 años y que se pretende alcanzar hoy.

Quizá sea como la base del arco iris, en la visión del poeta, quizá se aleje al mismo ritmo que pretendemos acercarnos. Tenemos la obligación de no pensar así. Tenemos la responsabilidad de acercarnos. Para eso debe servir la universidad pública reformista, para destrozar las utopías y volverlas realidades que reflejen una patria libre, soberana, justa y de iguales, donde las sonrisas satisfechas sean de todos.

\section{El modelo de universidad en la UNLP}

Las universidades de América Latina y el Caribe acordaron hace tiempo que la educación superior es un bien público y social, un derecho humano universal y una responsabilidad del Estado. Desde la década del '90 se defendió esa visión en cada debate dado en los foros educativos mundiales, contraponiendo este modelo al representado en la mayoría de los países del resto del mundo, que entiende el acceso a los conocimientos superiores como un bien selectivo, transable en el mercado.

La expectativa de nuestro desarrollo como país y nuestro progreso individual estuvo siempre basada en la igualdad universal de oportunidades. El ingreso irrestricto y la gratuidad de la enseñanza universitaria garantizados definitivamente por la Ley № 27204/2015 ya nacieron en las ideas de la Generación del ' 80 - Sarmiento, Avellaneda, Roca- plasmadas en 1884 en la Ley No 1420 de Educación Común con los preceptos de laica, obligatoria y gratuita para la educación primaria, extendida luego a la secundaria. Hoy a nadie se le ocurre proponer revisar los conceptos de gratuidad para la educación inicial, primaria y secundaria, y hay que asegurarse que en esa línea no queden bolsones de resistencia a la gratuidad de la enseñanza universitaria. El modelo nacional, largamente centenario, impone el derecho a la educación de todo el que esté dispuesto a hacer el esfuerzo de superarse para adquirir y acreditar más conocimientos.

La universidad debe ser un espacio para tener ideas y discutirlas, alejada del pensamiento único, promotora del pensamiento diverso, original y propio; caracterizada por estar llena de inquietudes, rechazos, audacias, escrúpulos y esperanzas que custodian el comportamiento ético, transparente, republicano y democrático de sus miembros. 
Debe ser firmemente inclusiva y entender a la educación como una línea ininterrumpida e ininterrumpible, que no debe cortarse por una falla del sistema que frene el proceso de toma de conocimientos de aquel que quiere seguir sumándolos, por un fracaso o deficiencia circunstancial. Si un estudiante no sabe lo suficiente para avanzar a un estadio superior en el proceso de su formación pero tiene la firme voluntad de resolver sus déficits esforzándose en sus estudios, la universidad debe darle siempre esa oportunidad. No puede dejarlo flotando en un limbo que no le permita ni retroceder ni avanzar. $Y$ eso debe suceder desde el ingreso hasta la finalización de sus estudios.

Esto no significa resignar calidad (ni pertinencia, ni la siempre bien defendida búsqueda de la excelencia), por el contrario, significa agregar responsabilidades al sistema. Ese es el verdadero contrato que se firmó cuando este modelo fue concebido para desarrollar al país y multiplicar las oportunidades para el progreso colectivo. La calidad y la masividad, asociadas al esfuerzo y al compromiso, son un conjunto indisoluble. Si existe uno de estos factores, necesariamente existen los otros en la universidad pública argentina. No puede considerarse de calidad la educación superior de un país que acepta dejar afuera a la mayoría de la población y no apunta a ofrecerle oportunidades de acceso, y es claro que cuando el acceso a la educación superior se limita a pocos, ella tiene características que la asemejan a un bien privado.

Este modelo inclusivo comprende brindar los conocimientos específicos para concebir al mejor profesional pero también generar el ambiente imprescindible para contribuir fuertemente a dotarlo de los valores fundamentales para consolidarlo como el mejor ciudadano. Pleno de solidaridad, consciente de su responsabilidad para los que menos tienen, tolerante hasta la exageración, sabiendo que el debate, el pensamiento diferente y las culturas generacionales siempre son más que el silencio homogéneo e indiferente. Consciente de que la democracia es un bien indispensable para poder alcanzar los objetivos más preciados, que costó mucho alcanzar y sostener y que no es una situación natural inextinguible si no la defendemos. Conocedor de que la defensa firme del medio ambiente es una condición de conciencia para dejarle a nuestros hijos y a sus hijos un mundo mejor que el que recibimos y en el que vivimos. Convencido de que los derechos humanos no solo significan la custodia de la memoria en la búsqueda de la verdad y de la justicia para saldar las deudas de un pasado injusto y doloroso, sino que acompañan cada acto de la vida, basados en la convivencia, en la búsqueda de la igualdad, en el reconocimiento del diferente, de las minorías, de cada uno de nosotros como un par.

\section{Los objetivos de la universidad pública}

Nuestra universidad tiene como objetivo primordial formar estudiantes en el pregrado, grado y posgrado para transformarlos en graduados firmes en sus conocimientos específicos y en sus condiciones y convicciones ciudadanas, comprometidos siempre con su comunidad. Debe buscar el crecimiento constante de la matrícula, la permanencia de los alumnos con avances sostenidos y continuos en sus carreras que permitan su culminación en tiempos acordes y conscientes del esfuerzo social y personal necesario para alcanzar su graduación. Ya no alcanza con sospechar que el solo paso por la universidad transforma positivamente al individuo. El país necesita de profesionales probos que apuntalen su transformación, y la universidad pública tiene la alta responsabilidad de proporcionarlos.

En un mundo donde el conocimiento, la ciencia y la tecnología juegan un papel de primer orden, el desarrollo y el fortalecimiento de la universidad pública constituyen elementos insustituibles para el avance social, la generación colectiva de riqueza, el robustecimiento de las identidades culturales, la cohesión social, la lucha contra la pobreza y el hambre, la prevención del cambio climático y la crisis energética. En este contexto, será necesario producir conocimientos útiles para el desarrollo del país y el bienestar de la humanidad. La colaboración con toda política pública apuntada a la necesidad social serán las grandes líneas para una investigación orientada, emergente de una sólida investigación básica y promotora de una investigación aplicada transferible y funcional a la concreción de estas metas. Asimismo, la universidad deberá ser actor fundamental en la integración de la red social intercambiando saberes y miradas como parte de un proceso formativo recíproco, especialmente con aquellos conciudadanos que menos tienen y sufren más necesidades. La extensión universitaria como parte del proceso formativo de estudiantes y docentes deberá ocupar un lugar de jerarquía. Pero este necesitará ampliarse con la capacitación extracurricular de aquellos sectores de la comunidad que precisen adquirir y certificar habilidades que ensanchen sus oportunidades en el mundo del trabajo y permitan mayores herramientas para una inserción social digna. La universidad pública tendrá que saber armonizar en su actividad la educación formal, la producción científica, tecnológica y artística, la transferencia de sus frutos y su integración académica a la región y al mundo, con la imperiosa cercanía a las necesidades coyunturales del pueblo del que proviene.

Finalmente, deberá responder en las crecientes demandas que le hace la sociedad y crecer en diversidad, flexibilidad y articulación. Formar parte de la comunidad académica mundial, integrar redes universitarias formativas, científicas y solidarias que posibiliten estar a la altura de nuestro tiempo y comprender los escenarios en los que es preciso evolucionar, movilizar estudiantes, profesores e investigadores en un intercambio productivo que sume siempre en la interacción, conscientes de que pertenecemos y construimos un modelo basado en el esfuerzo de la inclusión como prioridad. 


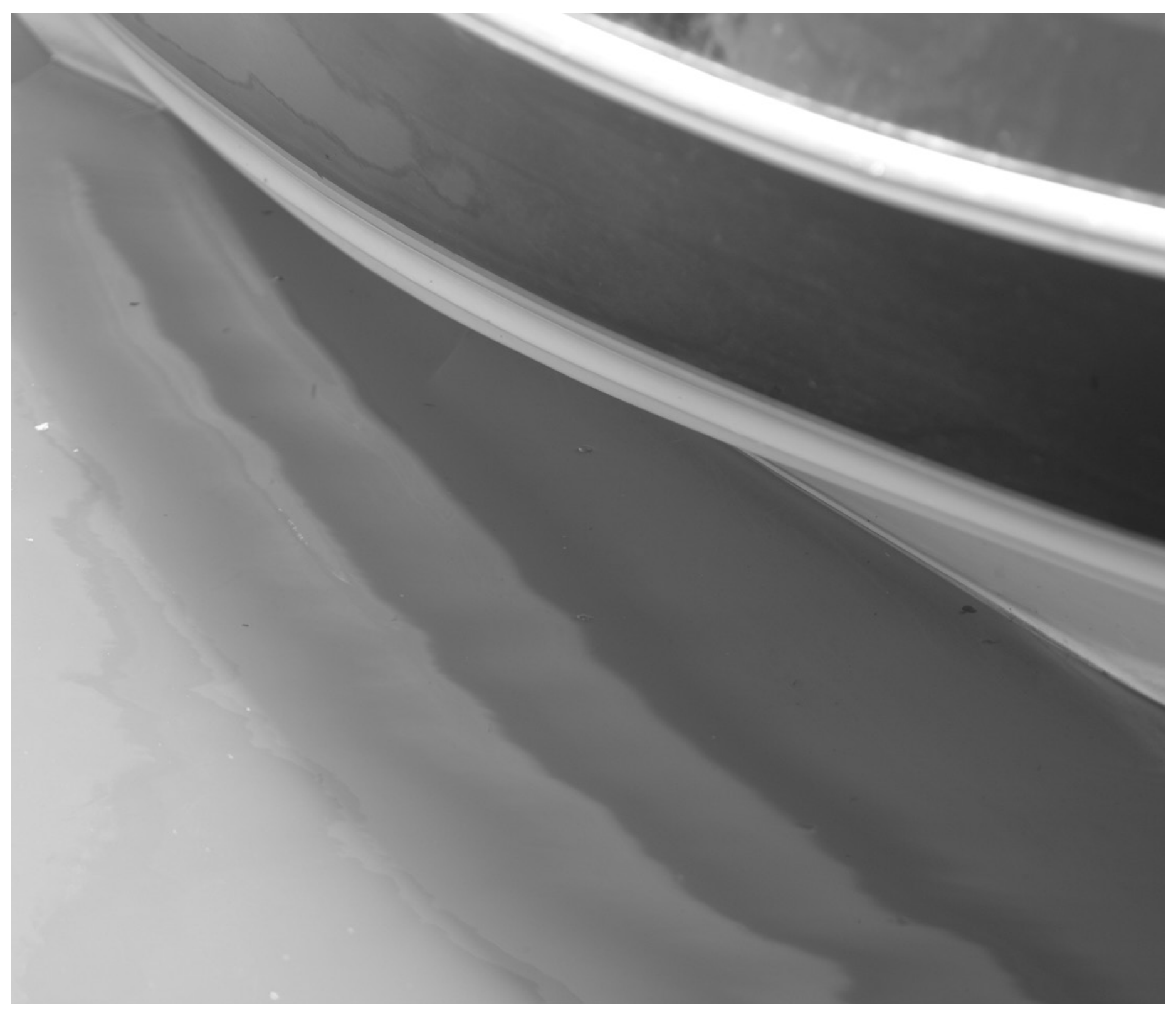

(c) Hugo Pascucci 


\section{Las prioridades en la UNLP}

Una institución educativa de gran complejidad como la UNLP afronta y desarrolla centenares de programas y proyectos emergentes de políticas académicas, científicas y sociales, que trazan objetivos acordes con las definiciones expuestas. El Plan Estratégico de la UNLP, instrumento de gestión participativa emergente de un proyecto institucional que comenzó a sistematizarse como herramienta en el año 2004, cuenta con más de 700 programas y proyectos que se renuevan con distinta periodicidad.

Todos coadyuvan a consolidar el modelo, los objetivos y los caminos expuestos para poder alcanzarlos. Todos estuvieron siempre presentes en el Plan y, sin embargo, su concreción o las condiciones del contexto definen prioridades.

El mayor rendimiento académico y el incremento de la graduación en tiempos proporcionados con la vida útil de cada ciclo formativo son una condición imprescindible para situar a nuestra universidad como una institución útil a la demanda insistente de un país y una sociedad que nos sostiene. Se deben atender las razones particulares y generar políticas para resolver las razones generales. No podemos darnos el lujo, como institución y como país, de tener un desgranamiento feroz, una duración laxa de las carreras, o un raquítico nivel de egreso.

El crecimiento de los desarrollos científicos y tecnológicos enfocados en las necesidades sociales, el cuidado ambiental y el desarrollo soberano del país, ocupan un lugar central en las políticas de la UNLP. Como universidad pública, debe asumirse como herramienta imprescindible para el progreso colectivo nacional, y para eso hay que producir conocimiento útil y transferirlo intensamente a las instituciones de la sociedad civil, a la pequeña y mediana empresa, y al Estado en todos sus niveles.

La capacitación extracurricular formalizada permite el acercamiento y la integración de sectores de la comunidad que siempre estuvieron alejados de la universidad pública, sin advertir —ambos— que la UNLP puede ser el soporte que dé sustento a sus expectativas de progreso. Aquí está uno de los grandes desafíos de este tiempo. Existe un sector enorme de la sociedad que no recorrerá el camino de la educación formal pero que necesita de la universidad y de lo que los universitarios saben hacer. Hombres y mujeres que, al mismo tiempo, precisan compartir lo que ellos saben y pueden hacer. Esa conjunción de saberes abrirá una magnífica oportunidad para consolidar una verdadera universidad popular, naturalizada en la vida cotidiana de nuestro pueblo.

La construcción e integración de redes sociales con los distintos actores institucionales formales y no formales de la región, nuestro afianzamiento como ámbito de debate e instrumento de acción colectiva y la multiplicación de vínculos activos y productivos con los distintos espacios de educación superior y ciencia en la región y el mundo, de manera de consolidar una agenda de intercambio orientada a la convergencia de necesidades concretas para alcanzar los objetivos trazados, conforman un núcleo de actividades que debe reforzarse y acrecentarse.

El crecimiento de los servicios estudiantiles, la continuidad del plan de obras, el mejoramiento constante de los sistemas de administración y finanzas, los beneficios, estabilidad y acompañamiento a la comunidad trabajadora docente y no docente, así como cada una de las actividades que hacen de la UNLP una institución activa y en crecimiento sostenido, son fundamentales en nuestra agenda.

Sin embargo, todas estas son condiciones que es necesario reunir para asumir con más fuerza la responsabilidad máxima de ser una institución comprometida en su presente y en su futuro con la construcción de oportunidades para nuestra gente y de alternativas de progreso para la Patria.

\section{Importancia y evolución de la extensión universitaria en la UNLP}

La extensión se moldeó a lo largo de los años según la forma institucional que fue tomando la propia Universidad. Por ello es necesario entender el origen y el desarrollo como institución. El mundo ha ido sumando conocimientos, acumulando organizaciones que, hace cientos de años, no eran universidades, eran academias, espacios vinculados a los sectores de poder. Cuando América Latina era colonia, la universidad nacía de la Iglesia o de la Corona. El ejemplo de Córdoba sea tal vez el que mejor plasma este proceso de colonización y búsqueda de riquezas que termina en esa provincia y en su capital crea la universidad en el año 1613. Aquella institución latinoamericana estaba pensada para formar los cuadros criollos que administraran la colonia, los cuadros eclesiásticos que sostuvieran la idea de religión, la idea papal, la idea del imperio religioso en América y para formar cuadros militares. Para eso era la universidad en América Latina. En este contexto empezó a gestarse la Reforma del '18.

Unas décadas antes, en el año 1890, se fundó en La Plata la Universidad, primero provincial, hasta que se nacionalizó en 1905. Hacia 1821, también en Argentina, se fundó la Universidad de Buenos Aires. Esta institución nació porque la incipiente república lo necesitaba. $Y$ con este tipo de universidades se produjo el primer toque de alerta a la concepción decimonónica de la universidad cordobesa y la aparición de una universidad para formar los cuadros necesarios para un Estado que estaba naciendo.

En estas primeras décadas del siglo XX el mundo estaba en ebullición: la Primera Guerra Mundial y la Revolución Rusa fueron acontecimientos históricos determinantes de la Reforma. En Argentina se terminaba de votar la Ley Sáenz Peña, Hipólito Yrigoyen era elegido presidente, por primera vez se había votado sin fraude. Dentro de las universidades, en este contexto, iba a ser inevitable el nacimiento de una contracultura opositora a la concepción claustral de la universidad de Córdoba. 
Surgieron grupos que bregarían por una movilidad social ascendente, que identificaron en el conocimiento una posibilidad de crecimiento, de desarrollo contra una universidad que se empecinaba en tener el poder muy concentrado y una enseñanza dirigida a defender sus propios intereses y no los intereses de esa sociedad pujante, creciente. $Y$ encontraron en Yrigoyen complicidad y respaldo. Estos sectores sociales ansiosos por un cambio fueron los que protagonizaron la Reforma del ' 18 en su nacimiento y desarrollo posterior. El movimiento se extendió rápidamente por toda América Latina y hoy las universidades reformistas están insertas en gran parte de la estructura universitaria latinoamericana.

El pensamiento reformista nació porque el gobierno de turno respaldó la transformación del sistema universitario. Sin embargo, muchas de las consignas plasmadas en el Manifiesto Liminar de la Reforma (como la autonomía universitaria, el cogobierno, la libertad de cátedra, el ingreso por concurso, el ingreso irrestricto, la gratuidad, la idea de que la universidad sea el ámbito natural de debate de los temas que le preocupan a la universidad y la extensión universitaria) no se pudieron implementar hasta bien avanzado el siglo XX.

La extensión universitaria no tuvo fuerzas durante el siglo XX, como tampoco lo tuvo la ciencia. Cuando el país empezaba a recuperar la idea del reformismo universitario se produjo el golpe de Onganía en 1966 y "La noche de los bastones largos". Estos trágicos acontecimientos ocasionaron la mayor fuga de cerebros que tuvo la Argentina. Las universidades, hasta ese momento, llevaban 15 años de investigación sistemática. Cuando las universidades empezaban a crecer y a consolidarse institucionalmente, el gobierno de facto lo destruyó todo. Después vino el "Proceso de Reorganización Nacional" en 1976, el golpe más sangriento de nuestra historia. Con la vuelta de la democracia, en 1983, las universidades iniciaron un proceso normalizador y recién entonces la universidad pública argentina tuvo la posibilidad de pensar en la investigación, la docencia y la extensión como pilares fundamentales para el desarrollo de un país.

En 1998, la Secretaría de Extensión de la UNLP contaba con una Dirección, que se denominaba Dirección de Extensión Cultural, y un Programa de Promoción de Proyectos de Extensión con presupuesto mínimo que subsidiaba tan solo 8 proyectos para el conjunto de la Universidad. Es decir, todo lo que hoy se naturaliza —el hecho de hacer converger la agenda científica y la extensionista con la agenda social- hace 20 años no estaba internalizado. Es cierto que en esa época la década menemista había producido muchas reacciones en la Universidad. La comunidad universitaria estaba en beligerancia con la Ley de Educación Superior, la sociedad estaba devastada y había que comprometerse en otros sentidos, había que defender la educación pública, libre y gratuita. Pero era un caldo de cultivo.
No había que convencer a nadie. Al contrario, la comunidad universitaria fue aprendiendo del propio convencimiento de que la extensión tenía que tener un fuerte contenido de compromiso, sobre todo con los sectores más vulnerables. Muy asociado en su función a los valores que la universidad imparte más allá de la especificidad de los conocimientos de las profesiones: la solidaridad, la tolerancia, el respeto por la opinión del otro, el respeto por las minorías en la misma dimensión que las mayorías, todo lo que hoy se enarbola como una concepción ideológica de la universidad que se anhela, lo fue absorbiendo la extensión. En ese momento fue una gran ofensiva del conjunto de la comunidad universitaria, de los docentes que empezaron a presionar para que su actividad se complementara no solo con la investigación sino también con la extensión.

Fue entonces que la Secretaría adquirió nuevas y mayores dimensiones, aunque aún faltaba: la mayoría de las facultades no tenía Secretaría de Extensión. Se comenzó con programas de capacitación pública y privada, se realizaron experiencias de capacitación de equipos de gestión de gobierno y cursos de alta gerencia pública. Las experiencias fueron muy interesantes en este sentido, muy activas, como lo fue la capacitación del cuerpo no docente. Se inició también un Programa de Vinculación con el Graduado que hoy depende de la Secretaría Académica. Avanzado el siglo XXI, empezó a funcionar la Expo Universidad, un evento de difusión de carreras que convoca hoy a más de diez mil estudiantes de escuelas públicas y privadas de La Plata y la región. Se creó a la par la Dirección de Vinculación Tecnológica. Si se compara a la distancia el estado actual de la extensión con su estado tan primitivo en la década del ' 90 , se podrá notar que es un hecho eminentemente contemporáneo.

Otorgar a la extensión la misma importancia que tienen la investigación y la docencia - a partir de la reforma del Estatuto de la UNLP en el año 2008- fue muy relevante en términos de madurez institucional. Es así que crece el bienestar universitario, se acrecienta la idea de inclusión y se define un concepto de universidad. La cultura extensionista es acercarse a la sociedad. Testigos de ello son todas las tecnologías que se han desarrollado en este último tiempo en el área, los trabajos comunitarios, el Consejo Social, la articulación con el Plan Argentina Trabaja, la Escuela de Oficios, la promoción de los programas y los proyectos de extensión. Todo esto hace que se comprenda que la universidad es la sociedad, no es que va a la sociedad. No hay nada que extender. Si al mundo se le ocurre decir que se llama extensión, se llamará extensión. Pero en la UNLP se la entiende como un intercambio: es decir y escuchar, escuchar más que decir. Aprender de los otros saberes y mezclarlos con los propios para conseguir saberes superiores, más beneficiosos para el desarrollo de nuestra sociedad.

La reforma del Estatuto produjo esa idea de la extensión, la idea del bienestar universitario, que abrió el Comedor Universitario, que abrió 


\section{G6}

Otorgar a la extensión la misma

importancia que tienen la investigación

y la docencia fue muy relevante en

términos de madurez institucional

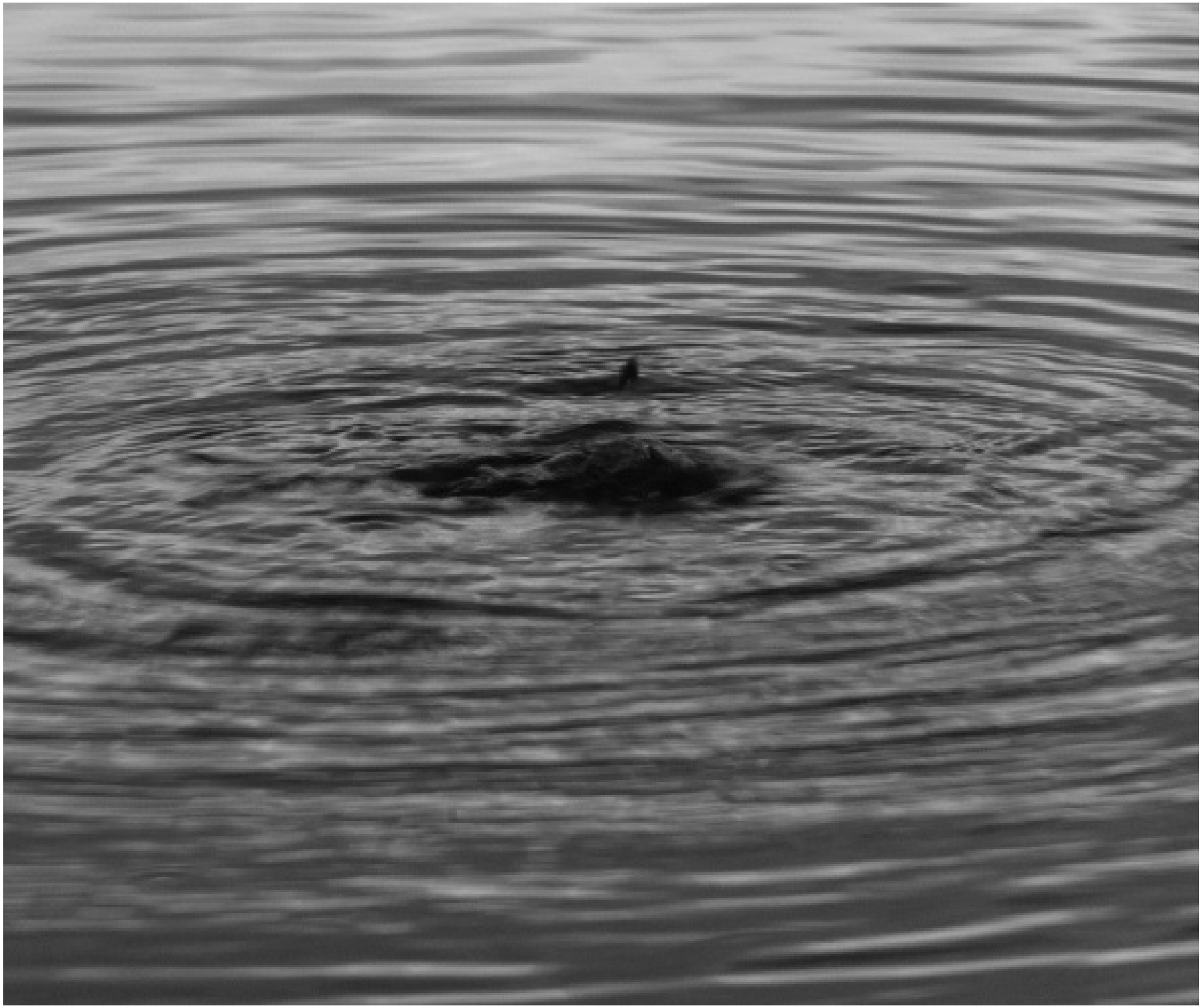

๑) Laura Malachesky 
el Albergue Universitario, que agregó democracia a la Universidad, que le incorporó al cogobierno los colegios universitarios de pregrado con voz y voto en el Consejo Superior, que incorporó a los no docentes, y que tiene hoy el cogobierno más completo que puede ofrecer una universidad argentina.

\section{Las mismas bases, nuevos desafíos}

La UNLP, pública y popular, autónoma y cogobernada, gratuita y de ingreso irrestricto, cumple y defiende los postulados de la Reforma Universitaria de 1918 en las postrimerías de su centenario. Aquellas prioridades que dieron fundamento al Plan Estratégico en 2004 han sido cubiertas. Hoy la Universidad se está reconfigurando. La UNLP tiene más de 105 mil alumnos en sus 17 facultades, y cada año se inscriben en promedio unos 25 mil jóvenes. Son cifras que la destacan en el concierto de las universidades nacionales y reflejan la eficacia de las políticas de inclusión y retención, que fueron pilares de los Planes Estratégicos precedentes. Es tiempo de asumir nuevas responsabilidades, de repensar la institución y rendir cuentas.

Las nuevas líneas del próximo Plan 2018-2022 deberán estar estrechamente ligadas a las problemáticas actuales: la calidad con inclusión, el rendimiento académico y la producción de graduados tendrán que ser metas irrenunciables desde lo académico. También será preciso buscar estrategias eficaces para lograr que la relación ingreso/egreso sea lo más estrecha posible, para ofrecer al país cada vez más profesionales de calidad. $Y$ finalmente será necesario promover cada vez mayor acceso a la Universidad de los sectores con menos oportunidades, y es aquí donde la educación no formal deberá ser una referencia tan importante como la educación formal.

\section{Referencias bibliográficas}

Altbach, P. y Davis, T. M. (2000). Desafío global y respuesta nacional. Notas para un diálogo internacional sobre educación superior. En Philip G. Altbach y McGill Peterson, P. (Eds.), Educación Superior en el siglo XXI. Desafío global y respuesta nacional (pp. 21-29). Traducción de Vera Waksman. Buenos Aires: Biblios. Arocena, R. y Sutz, J. (2001). La Universidad Latinoamericana del futuro. Tendencias, Escenarios, Alternativas. México: Colección UDUAL 11. Recuperado de http://www.oei.es/salactsi/sutzarocena00.htm (consultado el 9 de julio de 2013). Bayen, M. (1978). Historia de las Universidades. Traducción de A. Giralt Pont. Barcelona: Oikos-Tau SA.

Brovetto, J. (1998). La Educación Superior y el Futuro. Conferencia de clausura de la Conferencia Mundial sobre la Educación Superior La educación superior en el siglo XXI. Visión y acción. París: UNESCO.

Clark, B. (1997). Las universidades modernas: espacios de investigación y docencia. México: Coordinación de Humanidades. México: Universidad Nacional Autónoma de México.

Hübner Gallo, J. I. (1963). Esquema y objetivos de la Universidad Contemporánea Anales de la Facultad de Derecho Cuarta Época, III - Años 1961 a 1963, (3). Universidad de Chile. Recuperado de: http://www.analesderecho.uchile.cl/CDA/an_der issue/0,1301,ISID\%253D21,00.html (consultado el 8 de septiembre de 2007). Krotsch, P. (2001). Entrevista. Fundamentos en Humanidades, 2(3), 142-148. San Luis: Universidad Nacional de San Luis.

Kuhn, T. S. (1985 [1957]). The Copernican Revolution. Planetary Astronomy in the Development of Western Thought. Cambridge, Massachussets: Harvard University Press.

Le Goff, J. (1965). La Civilisation de l'Occident Médiéval. Paris: Grenoble Arthaud.
Lima, L. J. (1995). Aportes para un modelo de Universidad. Llamando a las Cosas por su Nombre. La Plata: Edulp.

Marcovitch, J. (2002). La universidad (im)posible. Madrid: OEA, OEI, Cambridge University Press.

Martínez Nogueira, R. (2003). La gestión universitaria: desafíos para las disciplinas organizacionales y administrativas. Ecos de Grado y Posgrados $2^{\circ} \mathrm{Ciclo}, 1$ (0, sep.dic.), 26-30. La Plata: Facultad de Ciencias Económicas de la UNLP.

Pirenne, H. (1992). Las ciudades de la Edad Media. Madrid: Alianza Editorial. Ribeiro, D. (1971). La Universidad Latinoamericana. Caracas: Universidad Central de Venezuela.

Rojas Mix, M. (2006). Siete Preguntas a la Educación Superior y otros ensayos. Rosario: UNR Editora.

— (2008). Para una filosofía de la universidad latinoamericana. Tucumán: Edunt. UNESCO (1995). Documento sobre Políticas para el Cambio y el Desarrollo de la Educación Superior. París: UNESCO.

(1998). Declaración Mundial sobre la Educación Superior en el Siglo XXI: Visión y Acción, París, 9 de octubre de 1998. Recuperado de: http://www.unesco. org/education/educprog/wche/declaration_spa.htm (consultado el 27 de octubre de 2009).

- (2009). Las Nuevas Dinámicas de la Educación Superior y de la Investigación para el Cambio Social y el Desarrollo. Conferencia Mundial de Educación Superior, Borrador Final del Preámbulo, comunicado el 8 de julio de 2009. París. UNESCO-IESALC (2008). Declaración de la conferencia regional de la Educación superior en América Latina y el Caribe, 4 al 6 de junio de 2008. Cartagena de Indias, Colombia. 